\title{
Investigation of Characteristics of Contact Bandages and Support Rollers of Rotating Technological Drums
}

\author{
Ivan V. Shrubchenko ${ }^{1}$, Andrey V. Hurtasenko ${ }^{1}$, Rashid R. Sharapov ${ }^{1}$, Tatiana A. Duyun ${ }^{1} \&$ Nikolay A. \\ Shchetinin $^{1}$ \\ ${ }^{1}$ Belgorod State Technological University named after V. G. Shukhov, 308012, Belgorod, Russia \\ Correspondence: Andrey V. Hurtasenko, Belgorod State Technological University named after V. G. Shukhov, \\ 308012, Belgorod, Russia.
}

Received: September 9, 2014

Accepted: September 16, $2014 \quad$ Online Published: December 29, 2014

doi:10.5539/mas.v9n1p195

URL: http://dx.doi.org/10.5539/mas.v9n1p195

\begin{abstract}
Efficient operation of rotating technological units in the period between overhauls largely depends on parts of backup abutments - bandages and rollers. At the same time an effect of rolling surfaces ground contact areas shape of these parts takes place, which in the end determine contact spot characteristics.

The purpose of this study is to investigate the influence of errors form surfaces bearing parts as well as their relative position on the stress- strain state in the contact zone. As a result of studies questions concerning contact surfaces modeling of bandages rolling surface and support roller of technological drums conditions, influence of their relative positioning on surface formation in a contact zone were resolved. Geometric and power characteristics of contact spot for various cases of positional relationship of bandages and rollers axles were obtained. The simulation results generally show that the length of the contact patch at small angles of rotation (3 degrees) does not change significantly; lowest stresses occur at the ends of the contact line, and change in length are unevenly; the maximum stress occurs at the center of the rotation axis and a third stress higher than the case where the axis are parallel. Contact patch shape is slightly different from the rectangular shape, but is asymmetric with respect to the axis of the bandage; a zone of low stresses at the ends of the contact spot, shows a change in the contact patch shape from a rectangle to an asymmetrical oval.
\end{abstract}

Keywords: support roller, form accuracy, contact spot, contact characteristics, surface stresses

\section{Introduction}

Technological drums (TD) for the implementation of physical-chemical treatment of materials are widely used in many industries (construction materials, chemical, mining, etc.). Their designs, as a rule, are inclined to the horizontal rotating welded drum mounted on several supports. Supports of technological drums include bandage attached to the housing and ensures the rigidity of the drum, and two support rollers mounted on rolling bearings (Shrubchenko, 2007). Bandages and rollers are cylindrical rolling surface. Support rollers can reach up to 2200 $\mathrm{mm}$ in diameter and bandages up to $8000 \mathrm{~mm}$. Width of the roller rolling surface is usually carried out at $100 \ldots$ $200 \mathrm{~mm}$ larger than the width of the bandage and reaches the size up to $1350 \mathrm{~mm}$. Bandages and rollers install, so that between the center of the bandage inner diameter and roller centers diameters form an angle $60-65^{\circ}$. Kiln rotary drive is carred out due to gear ring on the kiln body and drive gear which are installed somewhere in the middle of the kiln.

Support rollers are installed at the same distance relative to the vertical axis of the kiln for equal distribution of kiln weight. With such disposition, the bandage has no possibility of radial displacement, and will not hook in by rollers.

To avoid curvature axis of the kiln and to avoid overloading of individual supports, the axis of bearing rollers of the kiln supports must be mounted in a single plane with the horizontal component of the inclination angle equal to the angle of inclination of the kiln. Support rollers perceived weight of the rotary technology drum together with a bandage and raw materials inside. For technological drums domestic industry produces supports with different load capacity: 300 tons, 400 tons, 660 tons and 1,000 tons.

One of the features of TD operation is intensive wear of the rolling surface, which gradually becomes a saddle-shaped in a roller and convex in a bandage. Besides, at possible misalignment of the rollers relative to the 
axis TD wear increases, which leads to further distort of their shape (World Cement, 2008). The resulting defects significantly affect the operation of the kiln and cause the need for time-consuming and costly repairs.

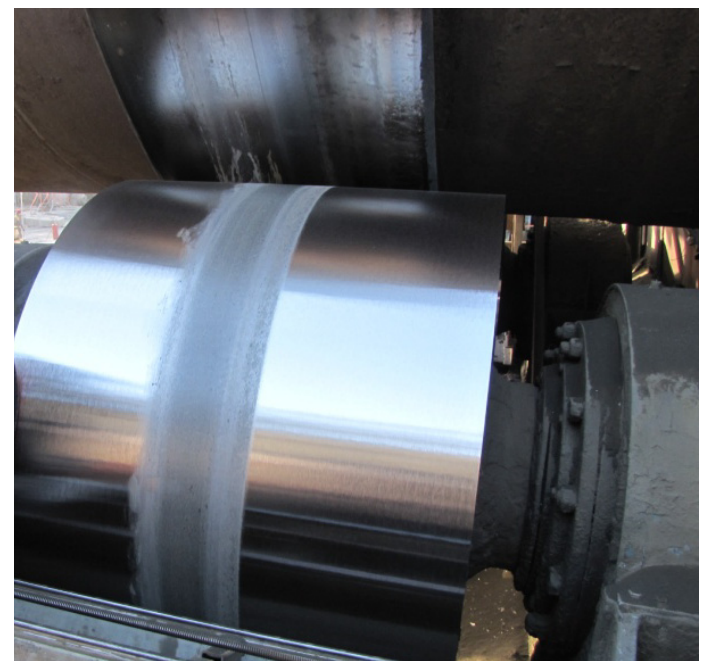

Figure 1. The shape and location of the contact spot of the support roller with bandage

In order to bandages and rollers can be operated within the regulatory period, it is necessary to ensure compliance with the shape and location of the contact (Figure 1) (Shrubchenko, 2007). The only parameter of the contact roller and bandage spot, due to direct measurement, is its axial length, which must not be less than $60 \%$ of the length of the bandage, the stress at the contact surface is not to exceed the yield strength of the material.

\section{Methods}

Determining the actual shape of contact spot of bandages and rollers TD, as well as specific pressures on its surface will allow taking into account the dimensions and tolerances of the individual parts of the supports, their masses to predict the expected wear of bearings, as well as the need and frequency of mechanical treatment in order to restore the desired shape by machining special portable machines. Thus there are also the problems of determining the degree of modifying the surfaces to provide the desired rolling contact condition, and the disclosure of the mechanism of formation constituting the rolling surfaces for the processing by the mobile equipment (Kolobov and Shrubchenko, 2006, Kuznetzova and Shrubchenko, 2006, Churtasenko and Pogonin, 2003, Pogonin and Churtasenko, 2003). It is of interest to identify the degree of influence on the contact spot formed patterns of distribution of contact stresses, elastic and thermal deformations. According generated during operation the actual shape of the support rollers may also be a necessary amendment to the definition of control relative rotation of their axes (Kuznetzova and Shrubchenko, 2006, Shrubchenko et al., 2013). If the guiding of support rollers surfaces and rolling bandage are circular, cylindrical line contact along the entire length of bandage perfectly possible with accurate installation rollers parallel to the axis of rotation of the kiln. Proper installation and adjustment of the mutual arrangement of the axes of support rollers and bandages needed to achieve the desired position of the axis of the unit process, and is a whole range of activities (FLSmidth A/S, 2011, IKDG, 2013). However, as was noted above, to achieve this condition is almost impossible, the contact area is significantly reduced. This in turn leads to peak stresses and progressive deformation of the rolling surfaces (IKDG, 2013). In the operation of kilns, as plastic deformation of surfaces rolling contact, conditions are constantly changing. At the same time it is possible to shift the contact spot to the end surfaces, reducing its area, and hence increase the surface pressure exceeds the allowed values.

In practice, due to the presence of various combinations of shapes of the rolling element produced in the process, and resulting in the reduction treatment, and the rotation surfaces of the rolling tires and bandages, various embodiments of the contact spot formation are possible. Therefore, a study of the conditions of their formation for the most typical cases are necessary (Kolobov, 2009):

- bandages and roller axis are parallel. In this case, the contact surface of the bandage and roller (TD) is a flat surface, the shape of the contact spot - a rectangle with a constant width $a$ and a length equal to the length of the bandage (Figure 2). Plane $n$, wherein the contact surface is perpendicular to the plane passing through the axis of the bandage and the roller, the contact spot axis is parallel to the axes of the bandage 
and the roller, and its projection on the plane $n$ coincides with the projections of the axes of the bandage and the roller;

- axis of bandage and roller lie in one plane, but not parallel. In this case, the contact spot is a planar symmetric figure, the axis of which lies in a plane passing through the axis of the bandage and the roller (Figure 2).

If we consider the projection of the contact area, drawn through the axis of the bandage and the roller, it will be a straight line. The width of the contact spot is variable along the axis. At the same operating voltage and distributed along the length of the contact load will be variable.

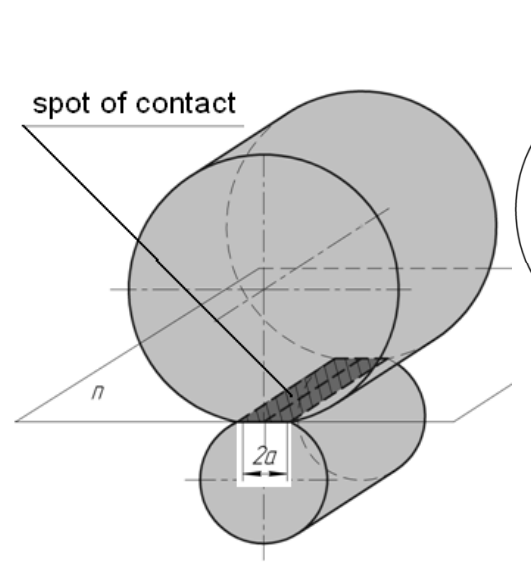

a)

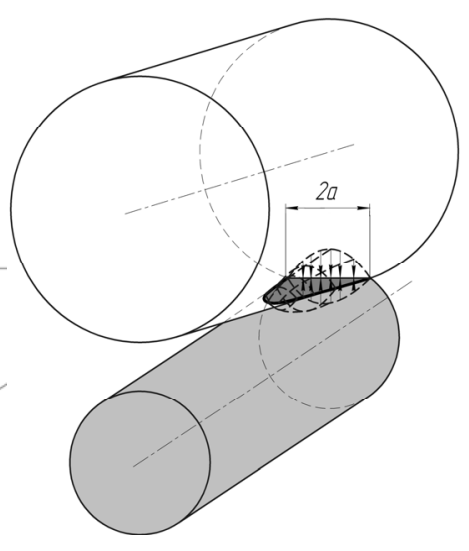

b)

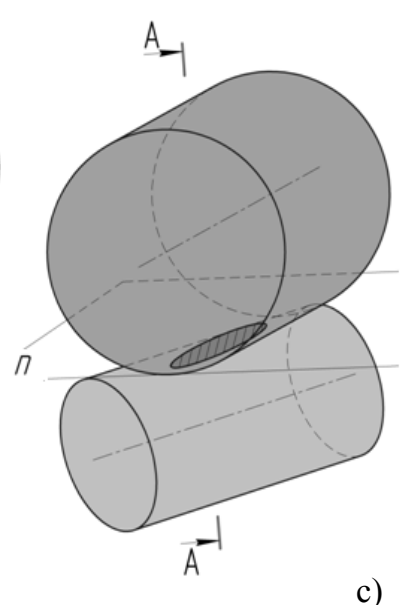

c)

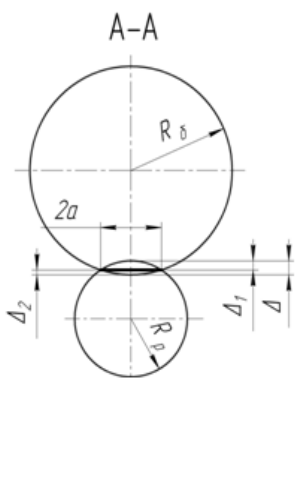

Figure 2. Variants of mutual arrangement of the axles and roller bandage:

a) Cylindrical surfaces contact of bandage and roller with parallel axes;

b) Bandage and roller contact axes which are nonparallel;

c) Bandage and roller contact with crossing axis.

In this case, it may occur stress concentration at one end of the bandage, whereby the operating conditions are unfavorable compared to the previously discussed case. The same character load distribution along the length of the contact may occur when the axis of the contact bodies are parallel, but one of them has a conical generatrix;

\section{- bandage and roller axis are crossing.}

In this case, contact spot will be located along a helical surface.

As can be seen in cross-section $A-A$ (Figure 2), a large fraction of the total deformation, resulting from convergence kinematic axes, will be deformation of the roller surface - $\Delta_{1}$, smaller - deformation of the bandage $\Delta_{2}$. Therefore, the axis of the imaginary cylinder, which is located on the surface contact area, obviously will not coincide with the reference axis of the bandage. In general case, the radius of the given cylinder, the correlation is $R_{C}>R_{b}$. For this case the axis of the contact spot will not coincide neither with any roller axis, nor with the bandage axis. Its position can be found geometrically (Figure 3) in the following manner: from the intersection of the projections of bandage and roller axes, on these axes should be postponed equal distances - $a$, and received points connect by a segment.

This segment is divided into parts $c$ and $d$, which are proportional to the diameter of bandage and roller:

$$
\frac{d}{c}=\frac{d_{1}}{c_{1}}=\frac{D_{b}}{D_{r}}
$$

Using the basic characteristics of contact spot (length - LC; maximum width 2a and area FC) (Figure 3) we can calculate the average stress across the contact area:

$$
\sigma_{a v g}=\frac{R}{F_{C}},
$$


where $R$ - reaction from the roller.
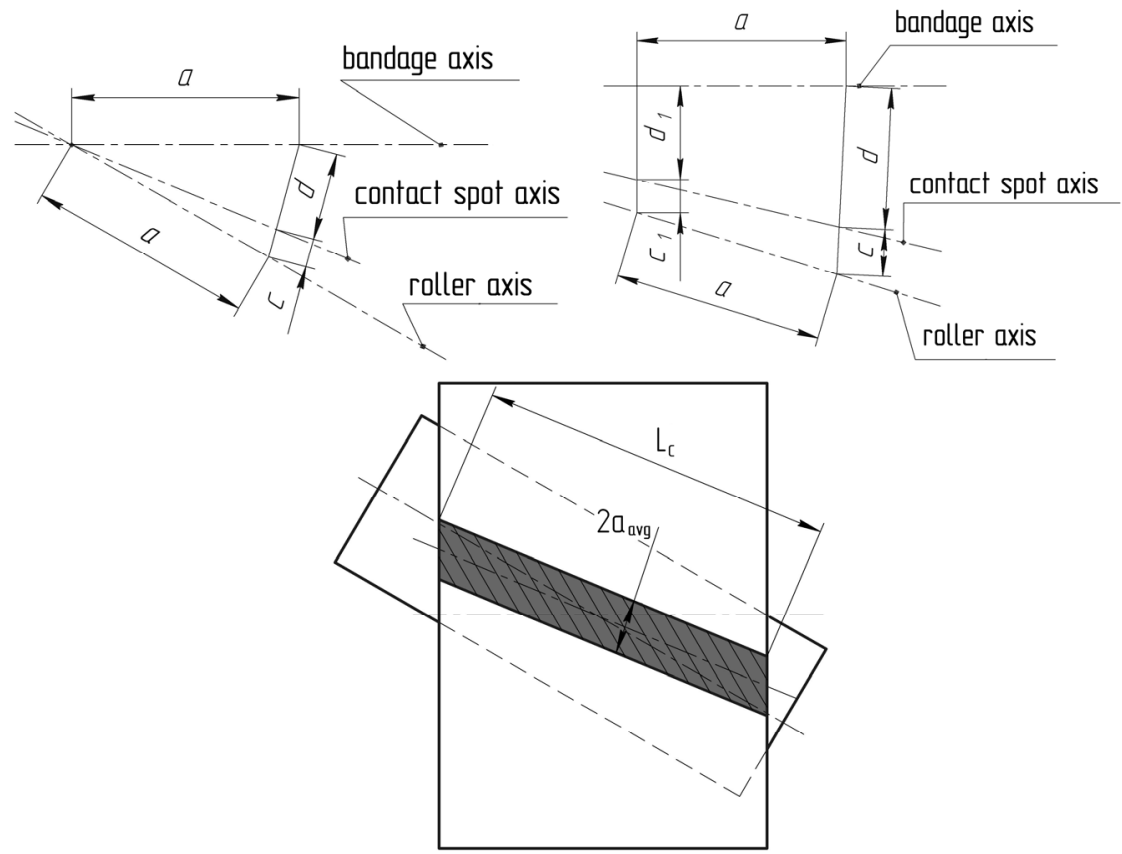

Figure 3. Finding the location of the contact spot symmetry axis. Possible contact spot rolling surfaces with skew axes

It should be keep in mind that for the condition when roller and bandage axis are crossing, may increase the contact area by modifying the shape of their rolling surfaces (Figure 3). In this case, the length of the contact spot may be longer than the bandage length, and therefore the conditions of their contact will be more favorable;

- bandage and roller axis are parallel and are skew. To determine the main characteristics of the contact (half-width of the contact spot $-a_{i}$; distributed load along the length of the contact $-p_{i}$; the load acting on support roller - $R$; maximum pressure - $q_{\max i}$ and contact pressure at any point in spots - $q_{i j}$ ) with nonparallelism and misalignment of roller and bandage axes we obtained the following dependences:

$$
\left\{\begin{array}{l}
a_{i}=\frac{2 \cdot \sqrt{0.5 \cdot \Delta_{i} \cdot\left(R_{1}+R_{2}-0.5 \cdot \Delta_{i}\right)}}{R_{1}+R_{2}-\Delta_{i}} \times \\
\times \sqrt{\left(R_{1}-0.5 \cdot \Delta_{i}\right) \cdot\left(R_{2}-0.5 \cdot \Delta_{i}\right)}, \\
p_{i}=\frac{a_{i}^{2} \cdot\left(R_{1}+R_{2}\right)}{2 \cdot 0.798^{2} \cdot R_{1} \cdot R_{2} \cdot\left(\theta_{1}+\theta_{2}\right)}, \\
R=\int_{0}^{L} p(x) d x, \\
q_{\max i}=\frac{2 \cdot p_{i}}{\pi \cdot a_{i}}, \\
q_{i j}=\frac{q_{\max i}}{a_{i}} \cdot \sqrt{a_{i}^{2}-y_{j}^{2}} .
\end{array}\right.
$$

To investigate the characteristics of bandages and support rollers contact and to predict the expected shape of the contact surfaces in the processing of rolling mobile equipment, it was developed a mathematical model and the program (Kolobov et al., 2013) to simulate the contact conditions in MathCAD environment.

The program allows to receive the diagrams of distribution of normal pressures along the contact spot in different shape forming surfaces of rolling bandages and support rollers in terms of turning their axes (Figure 4).

One of the possible tools to solve such problems is the computer simulation of contact interactions of bandage 
and roller. Formalization process of this phenomenon is not unique and requires special consideration.

At first sight, the representative results can be obtained in the case when you consider the impact of all of the physical processes occurring in the operation of TD. But such approach leads to cumbersome models, contradicting resources of modern computers. Therefore, a simplified model is a necessary condition. And in this way it is obviously possible exception of those factors that do not exert a significant influence on the phenomenon in question.

For this problem it should take into account the following factors:

- length and diameter of the drum, its angle to the horizon, the number of roller carriages and availability of hydrosupports;

- speed and smoothness of rotation, location and design of the drive;

- the temperature inside and outside of the drum shell and its thermal deformation;

- roller carriage design, the method of its fastening and features of the base.

Analyzing the first factor, we can conclude that getting the simplest model is possible by considering contact interactions for one support.

For the second factor we should exclude the effect of additional inertial loads, increasing the bearing forces and the wear rate of the contact surface.

This is explained by the fact that such dynamic phenomena are not essential for TD, working with a small speed up to $1.25 \mathrm{rev} / \mathrm{min}$, at constant loading mode and steady cycle.

Temperature support will obviously affect the contact conditions, and thermal deformation of the shell will lead to a change in the mutual arrangement of bandage and roller. Shell and bandage TD heating within (0.2-0.3) $\mathrm{T}_{\mathrm{mp}}$ - the melting point of the material, will also result in the reversion process - improving the structural quality of work-hardened material. Also, when the high temperature zone of bandage welds it will be observed material hardness changes. In accordance with the technical requirements, the difference in hardness of bandage parts included in one unit shall not exceed $10 \%$. Therefore, contact modeling should be made for conditions where thermal deformation of TD insignificant or their value is known and its influence can be taken into account in the source data as a special case of thermal and static equilibrium of support.

Analyzing the fourth factor it should be noted that carrying roller is support roller is pressed onto the axis, which is mounted on roller bearings or slider bearings. Both carrying rollers are mounted on the frame 4 of TD support. Besides the roller all the elements can be ignored during task solution in case when they have a substantial stiffness. Thus, considering all these assumptions, we can consider the contact of two solid steel cylindrical surfaces.

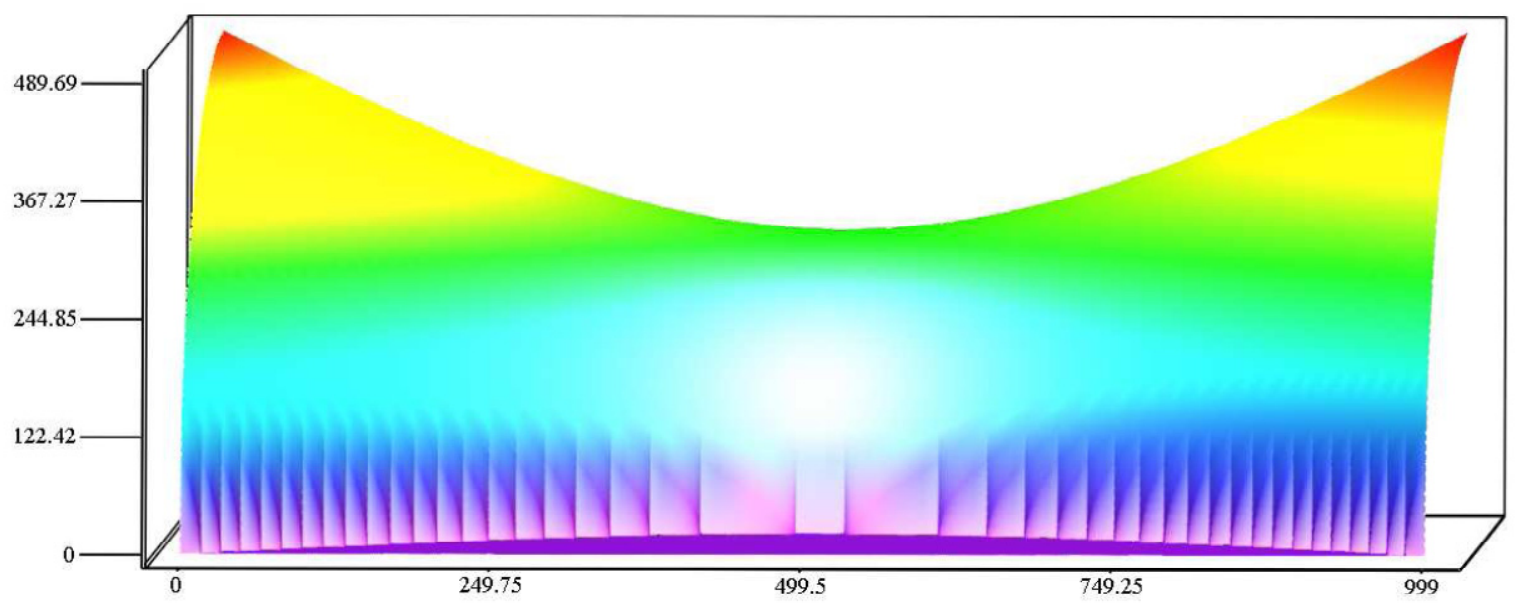

Figure 4. Distribution of normal stresses on the contact spot of bandage with support roller when the misalignment of axes

The bandage can be represented as a cylindrical segment, bounded by two parallel vertical planes. The radii of the outer and inner surfaces, as well as the width of the segment correspond to the actual design dimensions of 
the bandage. For example, in the calculations it was taken: bandage length $1000 \mathrm{~mm}$, outer diameter - $6100 \mathrm{~mm}$, internal diameter $-4550 \mathrm{~mm}$.

The roller can be imagined as a hollow cylinder with dimensions: length $1100 \mathrm{~mm}$, outer diameter - $1500 \mathrm{~mm}$, internal diameter $-600 \mathrm{~mm}$.

Create a finite element model using the NX Advanced Simulation (Siemens PLM Software Inc.) (Goncharov et al., 2012). NX Nastran was used as resolvent. Fixing was chosen as roller limitation - a cylindrical joint, i.e. the movement in all axes is fixed. For bandage we choose fixing on end faces - and allow only forward motion in the vertical direction, the remaining degrees of freedom are eliminated.

Between the parts it was chosen the object type simulation surface-to-surface contact. As initial area it was selected external cylindrical face of bandage and finite area was selected as external cylindrical face of roller (Figure 5).

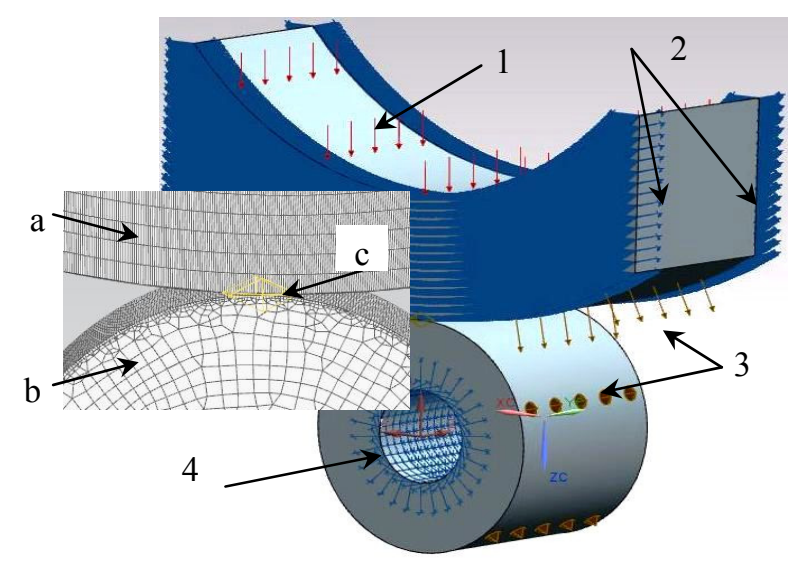

Figure 5. Calculation model: 1- loading, 2- bandage restriction on end faces, 3- surface- surface contact, 4- roller restriction: cylindrical joint.

Finite-element meshes: a - bandage mesh element size $80 \mathrm{~mm}$; b - roller mesh element size $80 \mathrm{~mm}$; c - mesh parameter 580 elements on edge.

Since the TD load acts on the inner surface of the bandage, it is believed that it is uniformly distributed on the inner surface of the segment and is directed vertically downwards. The magnitude of the acting load can be determined experimentally, or from normative data.

One of the important steps for the finite element analysis is to determine the size of 3D hexahedral mesh. Mesh parameters can be set for each part and, moreover, in different parts of these parts. Thus, roller surface is obtained with finer mesh cells (Figure 5). By the same method we should specify for the bandage mesh.

Furthermore, for obtaining a uniform stress distribution in contact zone "surface-to-surface" parameters specify so that the search range in all gaps and penetration were processed as contacts.

The calculation process may take different times, which is usually related to the number of elements of hexahedral mesh. After its ending the results are in a special "container", which contains the following data: moving the nodes, the stress on the elements, the stress on the elements / nodes, the reaction force on the nodes, the nodes of contact tracing, contact force across the nodes, the nodes on the contact pressure.

To estimate the rate of roller and bandage working surface deterioration, contact pressure data are used. They can be used in graphic and tabular form.

\section{Results}

Most clearly the contact pressures are presented in map form of the stress distribution on the contact area (Figure 6). The stresses indicated by a specific color which palette is specified as a scale on the same picture.

The resulting contact spot has a rectangular shape. Dark edging of light center corresponds to the zone which nodes are included in results, but they do not have stresses. For example, the calculation results for the above source data show that the maximum contact pressure is $346.67 \mathrm{MPa}$ (Figure 6, b). 
Let's verify this result on the Hertz model, received for the case of contact between two steel cylinders $(\mu=0.3)$ and repeatedly tested in practice. Contact stresses can be determined by the following dependence:

$$
\sigma_{\mathrm{H}}=0.418 \cdot\left[F \cdot E \cdot\left(d_{1}+d_{2}\right) /\left(d_{1} \cdot d_{2} \cdot b\right)\right]^{0.5}
$$

where $F=4 \mathrm{MN}$ - loading; $E=2 \cdot 10^{5} \mathrm{MPa}$ - modulus of elasticity; $d_{l}=1.5 \mathrm{~m} ; d_{2}=6.1 \mathrm{~m}$ - bandage and roller diameters respectively; $b=1 \mathrm{~m}-$ contact length. We obtain: $\sigma_{\mathrm{H}}=346.647 \mathrm{MPa}$. Thus, the divergence of results between the results obtained by the simulation and the calculation is not more than $2 \%$, which is quite acceptable.

Numerical values of stress field can be obtained using recognition results tab. These stresses are imported, for example, in Microsoft Excel (Microsoft Corporation) as a table with the possibility of subsequent processing. For example, from the stress distribution pattern in dangerous section along the length of the contact line is obtained (Figure 7, curve $0^{\circ}$ ). The obtained dependence shows that only at the ends of the bandage due to stress concentrations increase and remain constant at all other points.

Contact conditions modeling can be carried out and when roller and bandage axis do not lie in one plane (Figure 3). This often occurs in practice due to TD manufacturing and assembly error.

The results of calculations (Figure 7) obtained for rotation angles $3^{\circ}$ and $2^{\circ}$ show:

1) contact spot length at turning axes from 0 to $3^{\circ}$ is not significantly changed;

2) the lowest stresses at the ends of contact line, and by its length vary nonuniform;

3) the maximum stresses occur at the center of axes rotation and $25-30 \%$ higher than the stresses arising from parallel axes.

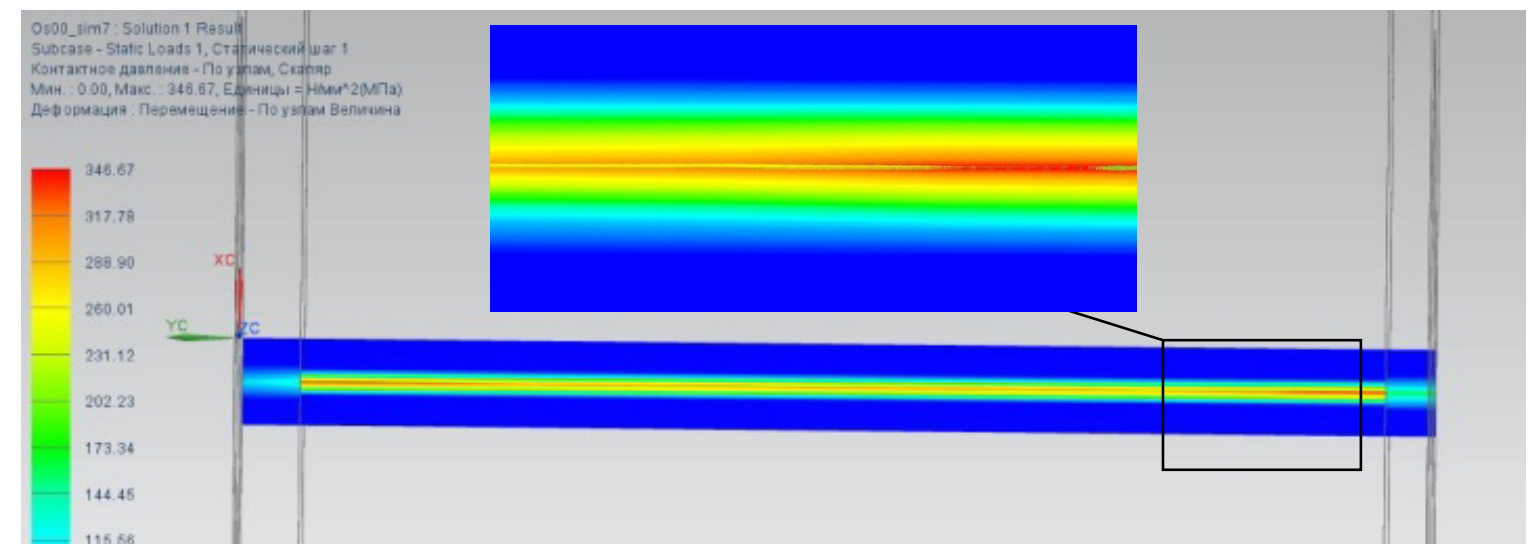

a)

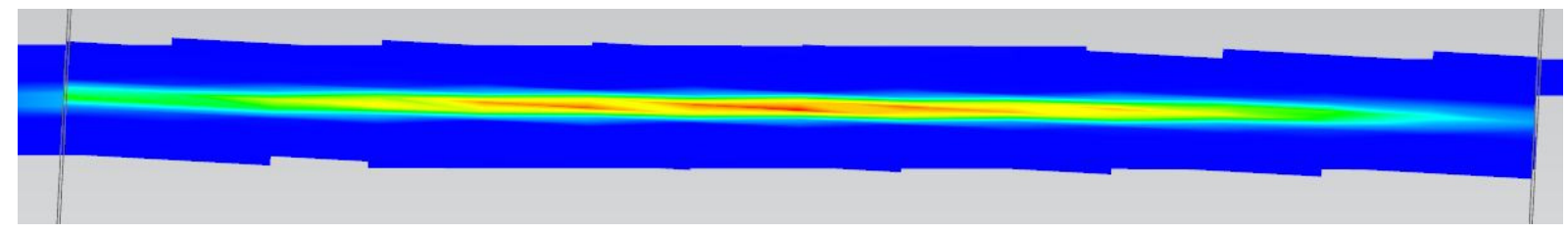

b)

Figure 6. Contact pressures map: a) in parallel axes; b) upon relative rotation of the bandage $3^{\circ}$ 


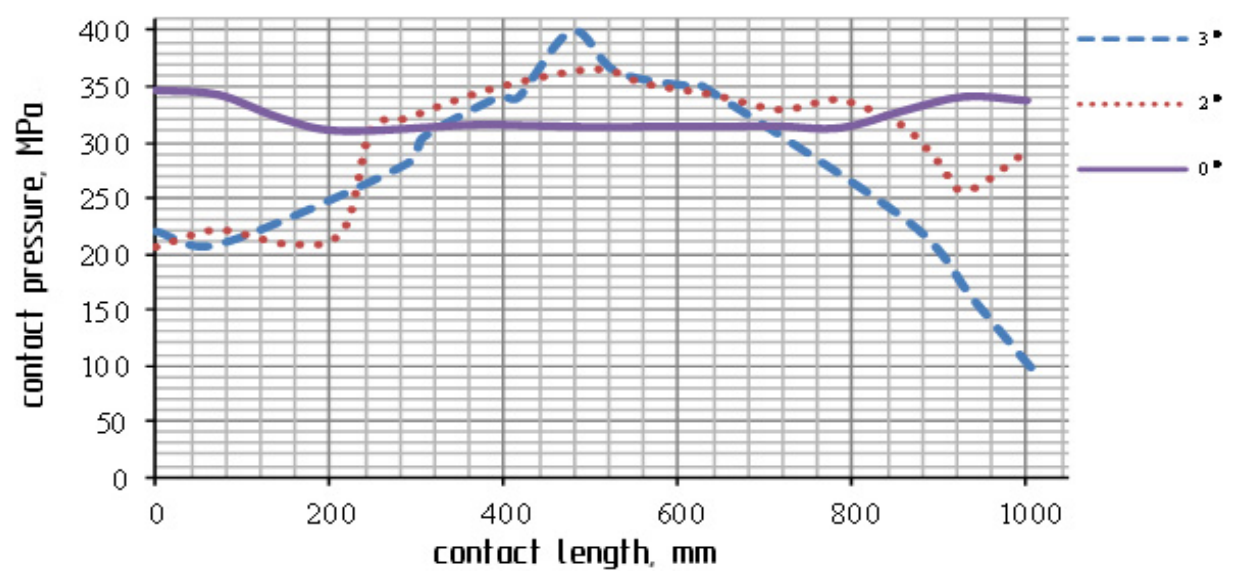

Figure 7. Maximum stress distribution on contact length

\section{Discussion}

The need for corrective maintenance of bandages and rollers bearing surfaces binds with the loss of their geometric accuracy during operation due to various factors - variables of dynamic loads, thermal effects, etc. (Kolobov, 2009). Nowadays mobile technologies, based on the usage of special turning lathes (Pelipenko, 1987) and grinding machines (Murygina, 2013), are used to restore the desired geometric shape.

In addition, one of the main task is to ensure the correct position of axles supporting parts, which together with the form of rolling surfaces affects the stress-strain state of parts and assemblies.

Research results presented in this paper, are good enough to confirm and extend knowledge regarding the physical state of the surface in the contact zone of bandages and rollers, which are presented elsewhere (IKDG, 2013). Inaccuracy of their relative position and the loss of geometric forms can lead to progressive deterioration of the bearing surfaces and increase energy costs for operation of the unit (Phillips Kiln Services Ltd, 2014, World Cement, 2008). Studies of the deflected mode of roller and bandage contact area, make it possible to determine the maximum allowable values of form and angles axes errors, which may take place during periods of their surfaces heavy wear.

\section{Conclusion}

These results indicate that the contact spot is slightly different from the rectangular shape, its width varies slightly (Figure 6, b), but the contact area is obviously asymmetrical relative to the bandage axis. Zone of low stress (less than $100 \mathrm{MPa}$ ) on the right end of the area shows the change in shape of the contact spot of a rectangular asymmetric ellipse. It should be noted that such maldistribution of stresses during operation will not be stable, since leads to the permanent wear and change in shape of contact surfaces.

Submitted mechanisms of investigation of conditions of large-size parts of TD bandages and rollers make it possible to optimize the shape of their rolling surfaces, which should ensure during processing of mobile equipment directly on the operating unit.

\section{References}

Churtasenko, A. V., \& Pogonin, A. A. (2003). Module technologies for large-size elements treatment in operation process, without theirs disassembling. Technologia i automatyzacja montazhu, 1, $42-44$.

FLSmidth, A/S. (2011). Rotary kilns for cement plants. FLSmidth A/S. Retrieved July 8, 2013, from http:/www.flsmidth.com/ /media/Brochures/Brochures\%20for\%20kilns\%20and\%20firing/RotaryKilnsforc ementplants.ashx

Goncharov, P. S., Artamonov, I. A., Halitov, T. F., Denisihin, S. V., \& Sotnik, D. E. (2012). NX Advanced Simulation. Reverse engineering. Moscow: DMK Press. Retrieved March 20, 2014, from http://www.industrialkiln.com/images/TireTaper.pdf

IKDG. (2013). TIRE/SUPPORT ROLLER TAPER. Industrial Kiln \& Dryer Group.

Kolobov, A. V. (2009). Technological support contact conditions during assembly and operation of technological supports drums. Unpublished dissertation in partial fulfilment of the requirements for the degree of Doctor 
of Philosophy, Belgorod State Technological University named after V.G.Shoukhov, Belgorod, Russia.

Kolobov, A. V., \& Shrubchenko, I. V. (2006). Influence of manufacture and installation inaccuracy of a special portable embedded machine for precision mold and turning rolling surfaces of technological drums. Education, science, production and management (issue v.1), pp: 328-334.

Kolobov, A. V., Shrubchenko, I. V., Hurtasenko, A. V., \& Voronkova, M. N. (2013). Certificate of state registration of the computer number 2013615272. Program for modeling contact conditions bandages and support rollers, applicant and rightholder: BSTU named after V.G. Shukhov. No2013612930, date 12.04 .2013

Kuznetzova, I. I., \& Shrubchenko, I. V. (2006). Influence of relative rotation and shape rolling surfaces supports of technological drums on their contact spot. Materials of international scientific-practical. conf. "Education, science, production and management" (issue 1), Stary Oskol, pp: 334-340.

Murygina, L. V. (2013). Shape recovery process of rolling bearings rotary kilns belt abrasive way. Unpublished dissertation in partial fulfilment of the requirements for the degree of Doctor of Philosophy, Belgorod State Technological University named after V.G.Shoukhov, Belgorod, Russia.

Pelipenko, N. A. (1987). Application of mobile units for modernization and rehabilitation of the equipment in the cement industry. Building materials industry. Overview, 1-2(15 Repair and maintenance of equipment): 57-58.

Phillips Kiln Services Ltd. (2014). How to repair tire and roller wear. Retrieved April 22, 2014, from http://www.pkse.co.uk/technical/tech_papers_display.php?How-to-repair-tire-and-roller-wear-2

Pogonin, A. A., \& Churtasenko, A. V. (2003). Accuracy assurance of dynamic settingc of portable technological modules. Technologia i automatyzacja montazhu, 2, 42-44.

Shrubchenko, I. V. (2007). Technological bases of forms and conditions support of the contact surfaces of rolling technological drums when processing with mobile equipment, Thesis of Prof. Dr. Ing., MAI, Moscow, Russia.

Shrubchenko, I. V., Hurtasenko, A. V., Voronkova, M. N., \& Murygina, L. V. (2013). Determining Bandages Rolling Surfaces Shape and Forming Bands and Support Rollers of Heavy Processing Barrels. Middle-East Journal of Scientific Research, 18(10), 1479-1485. Retrieved March 16, 2013, from http://www.idosi.org/mejsr/mejsr18(10)13/16.pdf

World, C. (2008). Comprehensive Kiln Alignment. World Cement. Retrieved February 20, 2013, from http://www.nakgroup.net/pdfs/world_cement_article.pdf

\section{Copyrights}

Copyright for this article is retained by the author(s), with first publication rights granted to the journal.

This is an open-access article distributed under the terms and conditions of the Creative Commons Attribution license (http://creativecommons.org/licenses/by/3.0/). 